\title{
Ireland set to adopt HPV vaccine for teenage boys policy
}

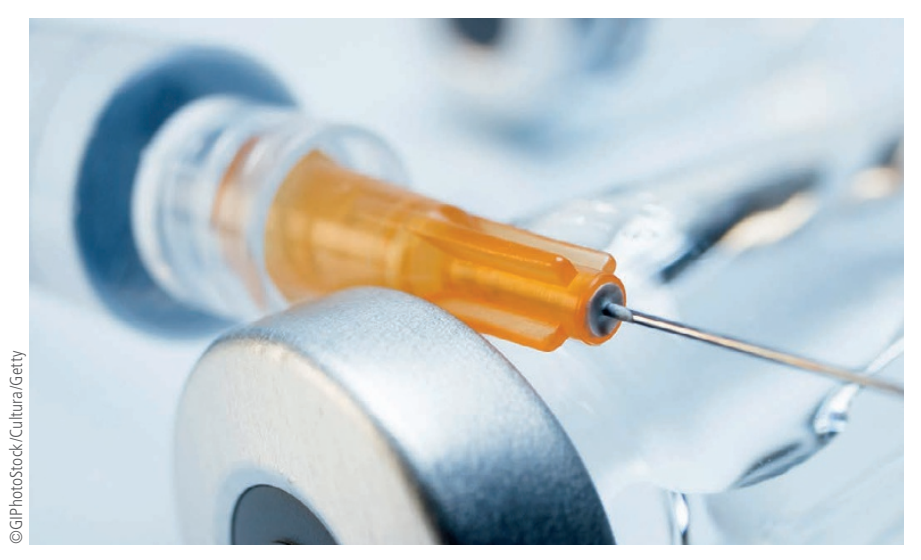

The Republic of Ireland looks set to follow the recent decision in the UK mainland to adopt a policy of offering the human papillomavirus (HPV) vaccine to teenage boys as well as girls.

On 24 July 2018, the UK government announced it was accepting the recommendation from the Joint Committee on Vaccination and Immunisation (JCVI) to extend the HPV vaccination to adolescent boys as well as girls in an attempt to reduce cancer cases including oral cancer. In a recent media briefing, the Republic's Taoiseach Leo Varadkar said: 'There's now a public consultation underway about that, which we anticipate will come out in favour of doing it too.

'So [health] Minister Harris and I spoke about this in the last couple of days, and we're going to put in train the procedures needed to introduce that next year to extend the vaccine to boys next year.

'There's a cost associated with it obviously in purchasing the vaccine, we need to negotiate payment with GPs and set up all the logistics around it. But we believe it's the right thing to do both in terms of reducing incidents of cervical cancer among women into the future but also HPV infections in men which give rise to anal cancer, penile cancer and head and neck cancers which can be particularly nasty. So glad we have the report and we intend to act on it and make it a reality in 2019.'
Irish Health Minister Simon Harris also issued a statement which mentioned a recently completed Health Technology Assessment made by the Health Information and Quality Authority (HIQA) to establish the clinical and cost-effectiveness of providing the HPV vaccine to boys.

'I am very encouraged to hear the HIQA assessment has found that vaccinating both boys and girls would have considerable health benefits and that it reiterates that the vaccine is safe and effective at preventing infection with HPV, said Harris.

'A public consultation is now underway, which is an important part of the process, and I encourage people to take this opportunity to give their views. The Government is very supportive of the extension of the HPV programme to boys.

'Cervical cancer impacts the lives of thousands of women in Ireland every year. Vaccination teams will be returning to schools in September to administer the HPV vaccine to girls in first year and I encourage parents to ensure that their daughters receive this important life-saving vaccine.'

Although England, Scotland and Wales have all committed to the policy, such a decision is still pending in Northern Ireland, although it appears promising.

A spokesperson for the Department of Health in Stormont, said: 'In light of the JCVI recommendation the department has directed that preparatory work be commenced to allow for the introduction of HPV in boys in Northern Ireland pending a decision by an incoming minister.'

Head of Cancer Prevention at campaigning group Cancer Focus Northern Ireland Gerry McElwee said: 'Extending the HPV vaccination to include adolescent boys is the optimal way to reduce preventable HPV related cancers.

'Cancer Focus NI has advocated extensively to have the HPV vaccine extended to boys. While we are delighted that the long-awaited breakthrough on gender-neutral vaccine has finally come in England, Scotland, Wales and, now, the Republic of Ireland, our focus is now on ensuring that Northern Ireland doesn't miss out.'

\section{Future plans for the BDA Benevolent Fund}

Leaders from the British Dental Association and BDA Benevolent Fund met on 5 September 2018 to discuss differing opinions about proposals which had been put forward for consideration at this year's BDA Ben Fund's AGM on 18 September 2018.

The BDA felt that the changes proposed by Trustees could have serious implications for the Fund's future. In particular, the BDA were concerned that the proposed amendments would:

- Remove the need to be a dentist in order to be a member

- Give the current trustees a veto over anyone they do not wish to be a member, and therefore control who will be the trustees of the future

- Change the requirement that rule changes must be approved by at least three-quarters of the members at an AGM to a simple majority.

The BDA felt that these changes would mean that a future board of trustees could, therefore, in theory restrict membership to those who would support the current board, remove all dentists from membership and change by a simple majority the purpose of the charity from supporting dentists to another charitable purpose.

However, following a meeting between BDA leaders and the BDA Benevolent Fund, held as this issue of the $B D J$ went to press on 5 September, the Trustees agreed to postpone the resolutions originally put forward for discussion at this year's AGM to allow further opportunity for consideration and review. It was decided that reform of the Ben Fund should be developed in partnership and revised proposals would instead be taken forward at the 2019 AGM.

A joint statement from Eddie Crouch, Vice Chair, British Dental Association, and Professor Ros Keeton, Chair, BDA Ben Fund, said:

'We are delighted to report there is a shared commitment to work together with common ground reached regarding the changes to the charity's membership, board size and administrative processes. 